\title{
Effect of gabapentin on haloperidol induced inhibition of conditioned avoidance response in rat
}

\author{
Nishant B. Bhansali ${ }^{a, *}$, Yash N. Goyal ${ }^{\mathrm{b}}$, Baluswamy Divakar ${ }^{\mathrm{c}}$, Sureshchandra D. Mistry ${ }^{\mathrm{d}}$, \\ Dinesh A. Chavda ${ }^{a}$, Jiyo Chacko ${ }^{\text {a }}$
}

\begin{abstract}
${ }^{a}$ Department of Pharmacology, M P Shah Medical College, Jamnagar - 361008, India, ${ }^{\mathrm{b}}$ Research Scientist, Torrent Pharmaceuticals, Ahmedabad, India,

${ }^{\mathrm{c}}$ Department of Pharmacology, Government Medical College, Surat, India,

${ }^{\mathrm{d}}$ Department of Pharmacology, GMERS Medical College,

Valsad, India
\end{abstract}

\section{Received: 16 October 2012 \\ Revised: 23 October 2012 \\ Accepted: 27 October 2012 \\ *Correspondence to: \\ Dr. Nishant B. Bhansali, \\ Email: \\ dr.idreamz1785@gmail.com}

\begin{abstract}
Background: Haloperidol, an antipsychotic adversely affects acquisition and retention of a learned task. We decided to test the effect of Gabapentin, a new anti-epileptic drug using conditioned avoidance response model with cook's pole climbing apparatus and haloperidol.

Methods: Four groups of six rats were taken for this purpose. All the rats were first given drugs for five days and then trained for a period of 15 days. Gabapentin was given in a dose of $100 \mathrm{mg} / \mathrm{kg}$ intra peritoneal, while haloperidol was given $0.5 \mathrm{mg} / \mathrm{kg}$ intra peritoneal.

Results: At the end of the training duration rats in the vehicle and gabapentin treated group achieved $\geq 85 \%$ acquisition responses. While the haloperidol and haloperidol + gabapentin group did not achieve the desired percentage of learning. A learning curve was plotted by using the percentage of conditioned responses in each group versus number of days. The mean \pm SD percentage of conditioned responses of day 14 and 15 were for haloperidol group 26.19 \pm 11.90 , for vehicle group $86.90 \pm 4.29$, for the gabapentin treated group 95.24 \pm 2.38 and for the gabapentin + haloperidol group $46.42 \pm 12.20$. These figures and the learning curve suggest that gabapentin treated rats had a better acquisition response and haloperidol depressed learning.

Conclusions: At the end of study duration we found that gabapentin significantly improved the acquisition response than the vehicle control group. Also haloperidol depressed the acquisition response. Gabapentin did not lead to reversal of haloperidol induced depression of acquisition process.
\end{abstract}

Keywords: Acquisition response, conditioned-avoidance response, gabapentin, haloperidol, Rat

\section{INTRODUCTION}

Conditioned avoidance response (CAR) is a well known technique to screen antipsychotic compounds in experimental animals. ${ }^{1,2}$ Telgedy et al and Saha et al have used this technique to study the process of acquisition. ${ }^{3,4}$ Haloperidol, an antipsychotic drug is shown to adversely affect acquisition and retention of a learned $\operatorname{task}^{5,6}$ in experimental animals.

Gabapentin (GBP), a GABA analogue was originally developed for the treatment of epilepsy and is widely used to relieve neuropathic pain especially in diabetic neuropathy. ${ }^{7}$ It is also found to be efficacious in migraine, bipolar disorder and social phobias. ${ }^{8}$ Gabapentin prevents seizures in a wide variety of animal models including generalized tonic-clonic and partial seizures. ${ }^{9}$ Because in all these conditions gabapentin is administered chronically for a longer duration, and gabapentin being a GABA analogue we decided to test its effect on acquisition of learning using CAR and Haloperidol.

We also thought that it would be worthwhile to explore whether gabapentin has any effects on acquisition response and whether it can enhance acquisition when it has been depressed by pretreatment with Haloperidol.

\section{METHODS}

Twenty four Charles Foster strain rats of either sex (excluding pregnant rats) weighing 250-350 gm, were used. Source of rats was animal house of our college. 
They were kept in cages housing three rats each, with free access to food and water. All the procedures were carried out in the light phase of a 12 hour light-dark cycle, starting from 8:00 am to 2:00 pm. All the procedures were carried out in the Research Laboratory of our department. All procedures carried out were in accordance with the CPCSEA Guidelines, with prior approval from the Institutional Animal Ethics Committee, of our medical college. Four groups containing six rats each were made. Each group was randomly selected.

Group A: Haloperidol $(0.5 \mathrm{mg} / \mathrm{kg}$, intra peritoneal $)$ served as a control group.

Group B: Vehicle group that received distilled water.

Group C: Gabapentin (100mg/kg orally) dissolved in distilled water.

Group D: Gabapentin (100mg/kg orally) dissolved in distilled water + Haloperidol $(0.5 \mathrm{mg} / \mathrm{kg}$ intra peritoneal $)$.

The dose of gabapentin as $100 \mathrm{mg} / \mathrm{kg}$ was taken from various studies. ${ }^{10,11}$ Haloperidol in $0.5 \mathrm{mg} / \mathrm{kg}$ is known to inhibit conditioned avoidance response significantly. ${ }^{12,13}$

\section{Acquisition experiment}

In these experiments each rat was given daily training session of 7 trials with inter-trial resting phase of about 1 minute. Rat was put in a Cook's Pole Climbing Apparatus (INCO). Two minutes were allowed for acclimatization. Buzzer (conditioned stimulus CS) was put on. After exposure to the buzzer (CS) for 5 seconds electrical foot shock (1mA AC, unconditioned stimulus US) was given through the stainless steel grill at the floor of the instrument. The rat tried to avoid the shock and tried to climb (response R) on the pole suspended from the roof of the instrument. Maximum period of exposure to the electrical foot shock along with the buzzer, in case the rat did not climb the pole, was 30 seconds. With continuous training every day animal was conditioned and started climbing the pole on exposure to buzzer (CS) only. Trials in which the rat climbed the pole in response to the buzzer (CS) only were counted for each rat. That is used to calculate the score of learning. Training was continued for duration of 15 days by which time the average score reached in the vicinity of maximum possible score as observed in our pilot experiments.

Drug or vehicle treatment was started 5 days prior to initiation of the training sessions to ensure that rats were exposed to this treatment sufficiently before training process sets in. Throughout the training period rats were administered drug or vehicle every day. Drug administration was done at least 1 hour after the training session. In a group where combination of gabapentin and haloperidol was administered, gabapentin was administered at least 30 minutes prior to haloperidol.

\section{Drugs}

Gabapentin (Sun Pharmaceuticals, India) and Haloperidol (RPG Pharmaceuticals, India) were used in the present study.

\section{Statistical analysis}

Mean \pm standard deviation percentage of conditioned response scores for each rat and each group were calculated. To assess the effect of treatment on acquisition response student's unpaired " $t$ " test was used. Also a learning curve showing the rate of acquisition was plotted by percentage of conditioned responses on each day versus the number of days (Figure 1).

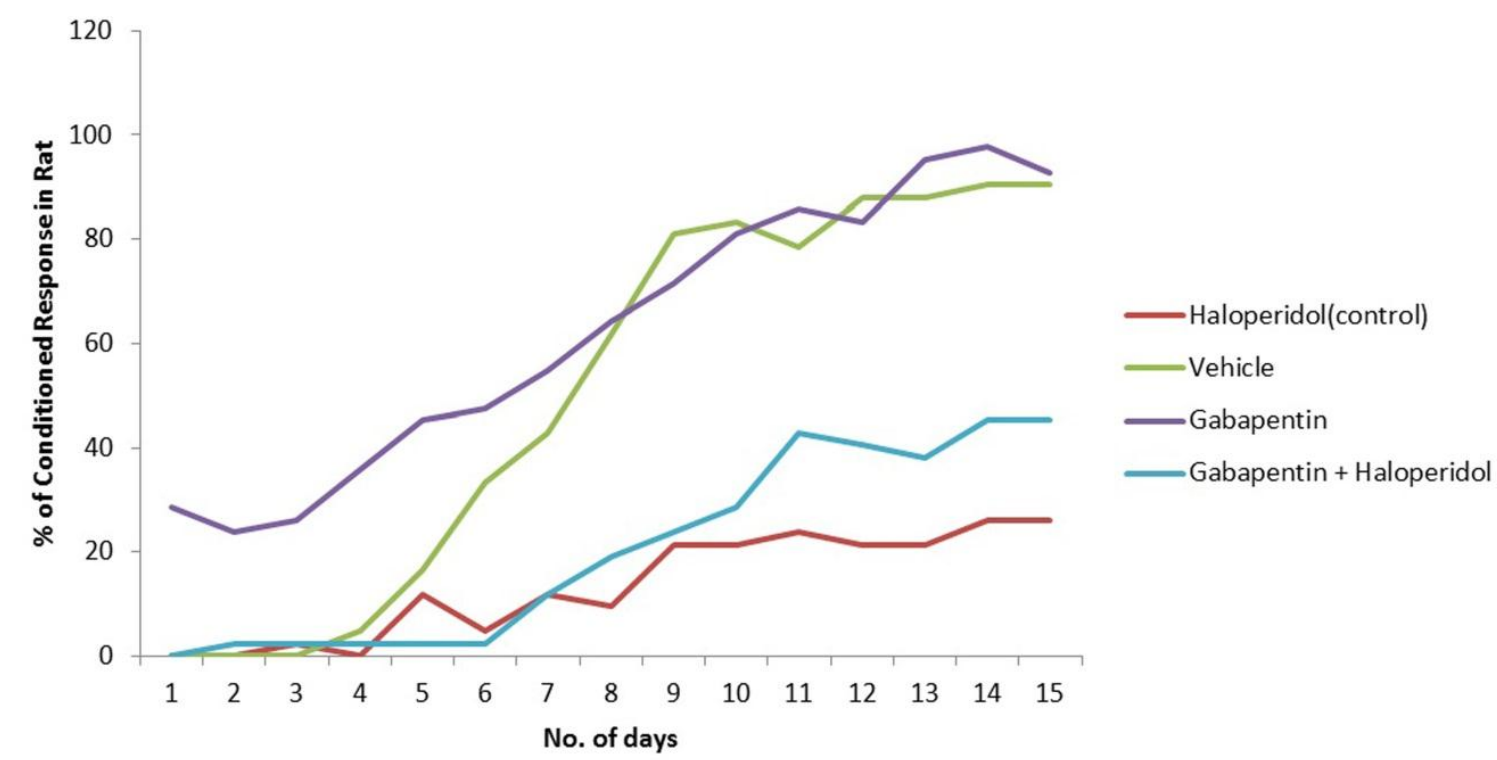

Figure 1: Learning curve of acquisition response in rat. 


\section{RESULTS}

In the vehicle group of rats we observed the learning to the extent of $\geq 85 \%$ of the maximal possible score at end of 15 days of learning span. In the group which received Haloperidol no muscular or loco motor deficiencies were observed during training sessions as the rats were able to climb the pole on unconditioned stimulus, but as the Figure I show no significant learning could be achieved in this group.

In the gabapentin treated group the acquisition was similar to that of the vehicle group, but the rate of acquisition was slightly better than the vehicle group. This effect can be seen in Figure I. While in the gabapentin + haloperidol group the rate of learning was not equivalent to vehicle group but it was better than the haloperidol group, suggesting that gabapentin might be antagonizing the haloperidol's inhibitory effect on acquisition response. This effect is also shown in Figure 1 .

Also the mean \pm standard deviation scores of Day 14 and 15 for each group were calculated, which are shown in the Table 1 .

Table 1: Mean \pm standard deviation percentage of conditioned responses in each group on day $14 \& 15$.

\begin{tabular}{|ll|}
\hline Groups & Mean \pm SD \\
\hline $\begin{array}{l}\text { A: Haloperidol as a } \\
\text { control group }\end{array}$ & $26.19 \pm 11.90$ \\
\hline $\begin{array}{l}\text { B: Vehicle group } \\
\text { (distilled water) }\end{array}$ & $86.90 \pm 4.29$ \\
\hline C: Gabapentin group & $95.24 \pm 2.38$ \\
\hline $\begin{array}{l}\text { D: Gabapentin }+ \\
\text { Haloperidol group }\end{array}$ & $46.42 \pm 12.20$ \\
\hline
\end{tabular}

Applying student's ' $t$ ' test between the groups. Haloperidol significantly depressed the acquisition response as compared to the vehicle group $(\mathrm{p}=0.0007$, $95 \%$ CI 32.52, 88.91). The acquisition of learning was significantly faster in gabapentin group than the haloperidol group ( $p=0.0002,95 \%$ CI 42.00, 96.10). But there was no significant difference between the vehicle group and the gabapentin group $(p=0.1204,95 \%$ CI -2.6 , 19.27) indicating that gabapentin did not affect the acquisition response. Applying student's 't' to the haloperidol and gabapentin + haloperidol groups we could see that gabapentin did not reverse the haloperidol's inhibition of conditioned avoidance response $(p=0.2626,95 \% \mathrm{CI}-17.74,58.21)$.

\section{DISCUSSION}

Using a single measurement of conditioning, the conclusion about acquisition response should be viewed skeptically. ${ }^{14}$ But still the criteria used in this study are quite reliable to draw inferences.

Results indicate that haloperidol affected the process of acquisition of conditioned avoidance response in rats. Various authors have supported this evidence in different studies. ${ }^{6,15,16}$ Of course the doses used in the various studies differ a lot. But the dose we used in the study also produces same effect. We also did not notice any loco motor or neurological deficit in the rats during the study period. During acquisition studies we noted that the development of correlation of the buzzer (CS), the shock (US) and the climbing on pole (R) was disrupted.

Dopamine receptor blockade in the limbic system by haloperidol must be the mechanism by which this effect was observed. The central dopamine system may play an important role in modulating memory process. ${ }^{17}$ Experiments have shown that blockade of pre-synaptic $\mathrm{D}_{2}$ receptors impaired both acquisition and retrieval stages of memory processes following an increase in dopamine release. ${ }^{18}$ Impairment of acquisition responses has been noted when injection of bovine serum albuminhaloperidol (BSA-HAL) is done in nucleus accumbens. ${ }^{19}$

Gabapentin, a gamma-amino butyric acid (GABA) structural analogue drug, introduced into clinical practice in the last decade, is used mainly in treatment of epilepsy. ${ }^{20}$ References on gabapentin show that apart from anticonvulsant efficacy, the drug also has a psychotropic effect which gives it an advantage in treatment of epileptic patients with concomitant affective disorders. ${ }^{21-25}$ Gabapentin improved the acquisition process in our study. Gabapentin is known not to disturb operating memory in healthy rats ${ }^{26}$ and to have a positive effect on memory consolidation and long-term memory in mice. Acosta et al showed memory improvement in CF-1 strain of mice in forced avoidance test following gabapentin administration. ${ }^{27}$

The mechanism by which gabapentin affects memory processes has not yet been well investigated. Drugs that enhance GABAergic transmission by interaction with $\mathrm{GABA}_{\mathrm{A}}$ or $\mathrm{GABA}_{\mathrm{B}}$ receptors are known to impair memory. ${ }^{28}$ Inhibitors of GABAergic transmission, on the other hand, improve memory in animal models. ${ }^{29}$ Acosta et al reasons that memory improvement he observed is not directly related to enhancement of GABAergic neurotransmission in the central nervous system (CNS) by gabapentin. ${ }^{27}$ Boccia et al hypothesized on effect of gabapentin on central cholinergic muscarinic receptors. Czubak A et al have showed that gabapentin did improve memory process in their study. ${ }^{30}$

However, gabapentin did not reverse the haloperidol induced inhibition of conditioned avoidance response in rats. It may be due to the fact that both the drugs are acting through different receptors and causing alteration in different neurotransmitters in the brain system. Also it may be due to the fact that the site of action for both the 
drugs may be different. Also the interaction of two drugs is also not well studied.

\section{CONCLUSION}

To conclude haloperidol depresses the conditioned learning in rats, while, gabapentin actually improved the acquisition response. The effect of gabapentin in retention of this acquired memory however remains to be determined in a different retention study. Also gabapentin does not cause reversal of haloperidol induced inhibition of conditioned response in rats. One important finding in our study was that the rate of acquisition response was faster in gabapentin group as compared to control group, which needs to be confirmed in similar study using better parameters like latency to stimuli and others.

Funding: No funding sources

Competing interests: None declared

Ethical approval: The study was approved by the Institutional Animal Ethics Committee

\section{REFERENCES}

1. Wadenberg ML. Conditioned avoidance response in the development of new antipsychotics. Curr Pharm Des 2010;16:358-70.

2. Natesan S, Reckless GE, Nobrega JN, Fletcher PJ, Kapur S. Dissociation between in vivo occupancy and functional antagonism of dopamine D2 receptors: comparing aripiprazole to other antipsychotics in animal models. Neuropsychopharmacology 2006;31:1854-63.

3. Telgedy G, Fekete M, Balazs M, Kadar T. Effect of a new antidepressant drug on active avoidance behavior in rats. Comparative study with tricyclic antidepressants. Arch Int Pharmacodyn Ther 1983;226:50-9.

4. Saha N, Datta H, Sharma PL. Effects of morphine, buprenorphine, pentazocine and nalorphine on acquisition and extinction of active avoidance response in rats. Indian $\mathrm{J}$ Physiol Pharmacol 1990;34:179-82.

5. Li M, He W, Mead A. Olanzapine and risperidone disrupt conditioned avoidance responding in phencyclidine or amphetamine pretreated rats by selectively weakening motivational salience of conditioned stimulus. Behav Pharmacol 2009;20:8498.

6. Lazarova-Bakarova MB, Petkova BP, Todorov IK, Petkov VD. Memory impairment induced by combined disturbance of noradrenergic and dopaminergic neurotransmission: effect of nootropic drugs. Acta Physiol Pharmacol Bulg 1991;17:29-34.

7. Rosenberg JM, Harrell C, Ristic H, Werner RA, de Rosayro AM. The effect of gabapentin on neuropathic pain. Clin J Pain 1997;13:251-5.

8. Young LT, Robb JC, Hasey GM, MacQueen GM, Patelis Siotis I, Marriott M, Joffe RT. Gabapentin as an adjunctive treatment in bipolar disorder. J Affect Disord 1999;55:73-7.

9. Taylor CP. Mechanisms of action of gabapentin. Rev Neurol (Paris) 1997;153 Suppl 1:S39-45.

10. Blake MG, Boccia MM, Acosta GB, Baratti CM. Posttraining administration of pentylenetetrazol dissociates gabapentin effects on memory consolidation from that on memory retrieval process in mice. Neurosci Lett 2004;368:211-5.

11. Boccia, MM, Kopf, SR, Baratti, CM. The enhancement of retention performance induced by picrotoxin in mice may be mediated through a release of endogenous vasopressin. Behav Pharmacol 1996;7:254-60.

12. Umathe SN, Wanjari MM, Manna SS, Jain NS. A possible participation of gonadotropin-releasing hormone in the neuroleptic and cataleptic effect of haloperidol. Neuropeptides 2009;43:251-7.

13. Ghosh MN. Fundamentals of experimental pharmacology. $5^{\text {th }}$ edition, Kolkata: Hilton \& Company; 2011.

14. Spear NE, Miller JS, Jagielo JA. Animal memory and learning. Ann Rev Psychol 1990;41:169-211.

15. Monti JM, Ruiz M. Increased disrupting effects of haloperidol on a conditioned avoidance response after 6-hydroxydopamine treatment. Pharmacol Biochem Behav 1975;3:943-5.

16. Yonko DI. Possible role of brain dopaminergic system in the memory effects of central stimulants. Methods Find Exp Clin Pharmacol 1984;6:235-9.

17. Ichihara K, Nabeshima T, Kameyama T. Opposite effects induced by low and high doses of apomorphine on single-trial passive avoidance learning in mice. Pharmacol Biochem Behav 1988;30:107-13.

18. Ichihara K, Nabeshima, T, Kameyama T. Effect of haloperidol, sulpiride and SCH 23390 on passive avoidance learning in mice. Eur $\mathrm{J}$ Pharmacol 1988;151:435-42.

19. Taghzouti K, Garrgues AM, Labouesse J, Moal M LE, Simon H. Bovine serum albumin - haloperidol and neurochemical effects following a single injection in nucleus accumbens. Life Sci 1987;40:127-37.

20. Dougherty JA, Rhoney DH. Gabapentin: a unique anti-epileptic agent. Neurol Res 2001; 23:821-9.

21. Dimond KR, Pande AC, Lamoreus L, Pierce MW. Effect of gabapentin (Neurontin) on mood and wellbeing in patients with epilepsy. Prog Neuropsycho pharmacol Biol Psychiatry 1996;20:407-17.

22. Harden CL, Pick LH. Alterations in mood and anxiety in epilepsy patients treated with gabapentin (Abstract). Epilepsia 1996;37(suppl):137.

23. Mortimore CM, Trimble M, Emmers E. Effect of gabapentin on cognition and quality of life in patients with epilepsy. Seizure 1998;7:359-64.

24. Dodrill CB, Arnett JL, Hayes AG, Garofalo EA, Greeley CA, Greiner MJ. Cognitive abilities and adjustment with gabapentin: results of a multisite study. Epilepsy Res 1999;35:109-21. 
25. Pande AC, Davidson JR, Jefferson JW, Janney CA, Katzelnick DJ, Weisler RH, et al. Treatment of social phobia with gabapentin: a placebo-controlled study. J Clin Psychopharmacol 1999;19:341-8.

26. Shannon HE, Love PL. Effects of antiepileptic drugs on working memory as assessed by spatial alternation performance in rats. Epilepsy Behav 2004;5:857-65.

27. Acosta GB, Boccia MM, Baratti CM. Gabapentin, an antiepileptic drug, improves memory storage in mice. Neurosci Lett 2000;279:173-6.

28. Brioni JD. Role of GABA during the multiple consolidation of memory. Drug Develop Res 1993;28:3-27.
29. Brioni JD, McGaugh JL. Post-training administration of GABAergic antagonists enhances retention of aversively motivated tasks. Psychopharmacology (Berl) 1988;96:505-10.

30. Czubak A, Nowakowska E, Kus K, Sadowski C, Matschay A. Effect of gabapentin on cognitive processes in rats not exposed and exposed to tobacco smoke during fetal life. Hum Exp Toxicol 2008;27:883-94.

doi: 10.5455/2319-2003.ijbcp004012

Cite this article as: Bhansali NB, Goyal YN, Divakar B, Mistry SD, Chavda DA, Chacko J. Effect of gabapentin on haloperidol induced inhibition of conditioned avoidance response in rat. Int $\mathrm{J}$ Basic Clin Pharmacol 2012;1:216-20. 